\title{
Employee Stock Options And Market Efficiency
}

Judy A. Laux, (E-mail: JLaux@ColoradoCollege.edu), Colorado College

Abdou N'Dir, Colorado College

\begin{abstract}
This study investigates market reaction to SFAS 123 Revised, "Share Based Payment," which requires companies to recognize the fair value of employee stock options as expense on the income statement. Using a sample of 128 firms for the 2004 and 2005 periods, we find that markets have efficiently incorporated information formerly disclosed only in footnotes to the financial statements, effectively nullifying the argument that formally recognizing the expense would have a deleterious effect on stock prices of firms offering this type of compensation.
\end{abstract}

\section{INTRODUCTION}

ccounting for employee stock options has been a controversial issue for several decades. Investors,
analysts, and the Financial Accounting Standards Board generally agree that compensation in the form of stock options has value and, consequently, should have an effect on a company's net income. Many firms favoring stock options as a means of employee compensation, however, do not want the high value of their compensation to become transparent through formal recognition in the financial statements. They argue that the resultant reduction in earnings would severely reduce stock prices and impede competitive success against foreign firms. While reported earnings per share would fall to lower levels, the claim that this would lead to lower stock prices presumes that the current earnings measure supplies new information to the market or that the market is inefficient at absorbing available information into security prices. Studies of market efficiency, however, suggest otherwise. Theory suggests that recognition of stock compensation would increase transparency and improve resource allocation. The current study investigates the market reaction to date. The following section offers a brief history of the accounting pronouncements related to employee stock options (ESOs) and is followed by a review of the theoretical constructs associated with formal recognition of ESOs. We then review the literature dedicated to this hot issue and offer an empirical section to discover whether market reaction to date has varied significantly from expectations.

\section{A HISTORY OF ESO PRONOUNCEMENTS}

For over thirty years the accounting profession has debated the appropriate measurement and disclosure for employee stock options. In 1972, the Accounting Principles Board issued APB 25, Accounting for Stock Issued to Employees, stating that stock-based compensation options should be measured using the "intrinsic value method." Under APB 25, stock-based compensation expense was the difference between the stock price and the option exercise price times the number of options at the measurement date, the date at which both the exercise price and the number of options are known. Thus, for employee stock option grants, the measurement date was the grant date, and under this standard, compensation expense typically equalled zero, because the exercise price was set equal to the stock price at the grant date, in most cases. Consequently, most companies were able to issue employee stock options without incurring an extra expense on the income statement.

The advent of option-pricing models by Black-Scholes and Lattice in 1973 sparked a debate about the valuation of employee stock options. Even though the models were designed for publicly traded call options that differed extensively from employee stock options, they nevertheless showed that options (even with restrictions) had a positive value above the difference between the stock price and the exercise price. After two decades of debate about 
the measurement issue, the Financial Accounting Standards Board issued Exposure Draft: Accounting for Stock-Based Compensation, a key feature of which was to require firms to recognize employee stock option compensation as expense using the fair value method, after adjusting for forfeiture and transferability at the grant date. The Exposure Draft met with much opposition, with both business executives and company managers arguing that expensing employee stock options using the fair value method would negatively affect their stock price, making it more difficult to acquire capital. Also at issue was the reliability of measuring the fair value of ESOs. Since risk-averse employees tend to exercise their stock options early, option-pricing models have a tendency to overstate the cost. The Accounting Standards Executive Committee, which originally had favored the proposal, voted 9 to 6 against, asserting that the measurement methods were simply unreliable.

In October 1995, the FASB issued Statement of Financial Accounting Standards No. 123: Accounting for Stock-Based Compensation (SFAS 123), accepting pro forma disclosures of earnings using fair value of stock-based compensation. The fair value was to be calculated using an options-pricing model that incorporated the option's exercise price, the current stock price, expected life of the options, dividend yield, risk-free interest rate, and stock price volatility. Thus compensation expense was to be disclosed in the footnotes but not formally recognized on the face of the income statement, even though the FASB strongly encouraged it.

One drawback of SFAS 123, accounting for stock volatility in the valuation process, was addressed in the revised version of that statement. This amendment, along with a number of other revisions, combined to form an extensive rewrite (295 pages), SFAS 123 (Revised, 2004), which has initiated two interpretations by the SEC since issuance. The statement requires formal expense recognition on the income statement based on fair value using a model that employs the six factors outlined above. Furthermore, it requires the use of expected, rather than historical, volatility in computing fair value, another measurement headache associated with adoption. The following section covers theoretical issues related to the accounting for ESOs.

\section{THEORETICAL CONCEPTS RELATED TO ESO ACCOUNTING}

The crux of the argument against formal expense recognition for stock-based compensation suggests a lack of faith in market efficiency. That is, efficient markets theory explicitly asserts that all available information is integrated into current market prices, and in the case of ESOs, fair value has been disclosed (albeit in footnote form) for a number of years. SFAS 123 (Revised) simply requires formal expense recognition on the face of the income statement. Thus, the fear of managers and corporate executives that expensing employee stock options will generate unfavorable earnings and lower stock prices relies on the assumption that analysts and other market participants have not read and quantified the footnote disclosures in establishing market prices.

From an accounting theory viewpoint, we can move through the famous "hierarchy of accounting qualities" found in the Statement of Financial Concepts No. 2 (1980, p. 20). The profession's "Conceptual Framework" offers a clear prescription: "[F]inancial reporting should provide information that is useful to present and potential investors, creditors, and other users for making rational investment and credit decisions" [Delaney et al, pp. 21-22]. In particular, the ability to forecast future cash flows is paramount. To the extent an accounting element is measurable and reportable, it should be recognized officially in the statements. In addition, the matching principle dictates that expenses be matched with revenues whenever it is reasonable and relevant. In the case of ESOs, SFAS 123 insufficiently incorporates the goals and transparency of financial reporting because the information is reported only in the footnotes. The revised statement, however, states that equity instruments received in exchange for services are now subject to the recognition and measurement requirements defined by GAAP. While the associated measurement issues (i.e., the appropriateness of the fair value model) might challenge the reliability of the information, the FASB has taken a clear stand on the relevance of the information to users. The following section examines empirical and theoretical studies pertaining to accounting for employee stock options.

\section{REVIEW OF LITERATURE}

Articles about accounting for employee stock options divide themselves neatly into two categories: Those aimed at the theoretical constructs underlying the topic and empirical investigations of the effects of accounting 
changes. For Wallman [1995], one of several authors to argue that disclosure (rather than recognition) is sufficient, decision usefulness reigns, and disclosure offers the relevant information. His primary concern lies with the inability of accounting reporting to keep up with the pace of a rapidly changing business environment. Harter and Harikumar [2002] make a similar argument - one specific to ESO accounting — when they point out that even the new statement fails to go far enough, because recognition of fair value at the time of grant ignores the fact that option values change over time. They promote yearly adjustment that recalculates compensation expense and adheres more closely to the matching principle. In short, the incremental approach so common to the accounting profession once again represents a target for criticism.

Mano and Mouritsen [2004] argue that, rather than squabbling over the valuation method for measuring stock options expense, the FASB should stop issuing rules and set standards based on principles, focusing on the substance of transactions and allowing accountants and auditors some leeway to use their own judgment in measuring values such as ESO expense. They contend that this would create better financial reports and greater transparency, helping financial statement users to get a candid description of the health of a business [Mano and Mouritsen, 55-56]. In two separate articles, Deshmukh et al express their general belief in market efficiency, stating that recognition will not enhance the functioning of equity markets (which already have adjusted prices for the cash flow effects of stock options); expensing ESOs voluntarily, however, would be more likely to happen in certain kinds of companies - ones that are more transparent in their general reporting, in which managers' and investors' interests are closely aligned, and where good corporate governance is in evidence [Deshmukh et al, 2002 and 2004]. This observation suggests a signaling effect in the full disclosure that accompanies formal expense recognition. Finally, Bodie et al [2003] and Asness [2004] make persuasive arguments that stock options are undeniably an expense, can be reasonably estimated, and are not adequately disclosed in footnote form. Furthermore, expensing them will not cause undue harm to young businesses.

Of the empirical works on ESO accounting, several focus on the association between employee stock option value and firm share prices. Aboody [1996] finds that firms' ESO values are negatively correlated with their stock prices and that options in their early vesting stages have a positive effect on firm value, but options vested in-themoney are considered a net cost by the firm's shareholders. He surmises that ESOs have two offsetting effects on stock prices: a dilution effect (the cost) and an incentive (the benefit); hence, stock prices and the value of outstanding options have a significant negative relationship, because the cost of the options is greater than their benefit, resulting in a net expense. Aboody, Barth, and Kasznik [2001] also investigate the relationship between equity market values and the unrecognized employee compensation expense in determining net income under SFAS 123. Their findings indicate that investors view unrecognized compensation disclosed in SFAS 123 as an expense and that its measurement is sufficiently reliable to be incorporated in their valuation. The results also find a negative association between stock-based compensation expense and equity values. On the contrary, Rees and Stott [1998] find a positive relationship between ESO expense and firm value, suggesting that the incentive benefit from employee stock options is greater than the associated costs. They also find evidence that small companies with high growth potential benefit more from ESOs than larger companies, because high-growth companies need more cash and, by employing ESOs, can save cash and still retain and attract top talent [Rees and Stott, 1-4, 18]. While both Balsam et al [2004] and Li [2002] find that stock options expense, whether disclosed in the footnotes or recognized in the income statement, is considered a cost and valued accordingly by the market, Bell et al [2001] contend that options are not priced like an expense or cost but, rather, as an asset. This supports the views apparently held by high-tech firms that ESOs warrant classification as an intangible asset, an investment highly valued by firms [Bell et al, 26-27].

Both theoretical relationships and empirical investigation appear in a study by Dechow, Hutton, and Sloan [1996]. They develop three research questions to evaluate the presumed economic consequences of expense recognition. The first investigates the cost of top-executive compensation, hypothesizing that firms in which top executives received large amounts of ESOs were more likely to lobby against mandatory expensing (upheld in the findings). A second hypothesizes that expensing stock options would result in lower stock prices and a higher cost of capital (not supported), and a third (called the contracting cost approach) suggests that firms might face tight retained earnings-based debt covenants (again, not supported by the evidence). 
The research outlined above has demonstrated both theoretical and empirical standpoints concerning the economic effect on firms of expensing stock options. Following closely on earlier academic research, the current study examines the FASB's announcement date to begin mandatory expensing in December 2004 in comparison with the market reaction in 2005 to reporting the cost associated with stock options cost on the income statement. The goal is to run a comparison model equation to investigate market reaction during 2004 and 2005, as described in the following section.

\section{EMPIRICAL STUDY}

As outlined in previous sections, the fervent opposition to full recognition of employee stock option expense claims that such formal recognition will be detrimental to firms' future earnings and, therefore, common share prices. The current study hypothesizes otherwise. We contend that the market is already efficient with respect to the information formerly disclosed in the footnotes and that moving from disclosure to recognition will not make the market behave disadvantageously for firms.

The data selected for the regression statistical model were based on sample firms obtained from ValueLine, the source of the control variable "Growth." This sample was then compared for accuracy with the SEC 10-Q filings obtained from the SEC and Mergentonline websites. To be retained in the final sample, a firm had to disclose the following information (for both 2004 and 2005) in their notes to condensed consolidated financial statements: 1) latest quarter (categorized as 3, 6, 9 months ended quarter) fiscal year end, 2) pro-forma disclosed compensation expense determined under the fair value method, net of taxes, 3) did not adopt the stock-based recognition method prior to the FASB's announcement mandating full recognition, 4) a positive net income and earnings per share, and 4) a book value calculated from Hoovers. This resulted in a preliminary sample of 128 companies in 2004 and 2005. Due to insufficient data and to control for extreme outliers from the regression residual graph, the initial sample was further reduced to a final sample of 121 (2005) and 122 (2004) companies. Stock prices were obtained from the WSJ.com website for their last quarter ended period. Book values were manually calculated as total assets minus total liabilities, and stock-based compensation expense and book value were calculated per common share outstanding.

As noted earlier, the point of this study is to add to the literature by providing statistical evidence to investigate the value relevance of stock-based compensation following the FASB's issuance of SFAS No. 123R. Balsam et al used a regression model to investigate the difference between stock-based disclosure and stock-based recognition [Balsam et al, 2004, 14-17]. This research uses a simplified (but closely related) model to address the hypothesis of this paper. To test the value-relevance of the ESO expense as if it had been expensed on the income statement, the following regressions were used:

$P_{i t}=a_{0}+a_{1} B V_{i t}+a_{2} E S_{i t}+a_{3} E S S O_{i t}+a_{4} G R O W T H_{i t}+e_{1 i t}$

$\mathrm{P}_{\mathrm{it}}=\mathrm{a}_{0}+\mathrm{a}_{1} \mathrm{BV}_{\mathrm{it}}+\mathrm{a}_{2} \mathrm{EPS}_{\mathrm{it}}+\mathrm{a}_{3} \mathrm{ESO}_{\mathrm{it}}+\mathrm{e}_{1 \mathrm{it}}$

where $\mathrm{P}$ is share price at the end of the fiscal year quarter; BV is book value (total assets minus total liabilities) per share; EPS is earnings per share from continuing operations less any recognized stock-based compensation expense; ESO is per-share unrecognized stock-based compensation at fiscal year end determined under the fair value method, net of tax effect; GROWTH is a proxy (ValueLine annual earnings rate growth forecast variable); $\square \square$ is the random error term.

Based on previous research studies, the coefficients book value (BV), earnings per share (EPS), and earnings growth (Growth) are predicted to be positive. Given the condition that stock-based compensation does not have the same characteristics as other income statement expenses because of its potential incentive effect on firm value, the coefficient ESO is also predicted to be positive. In addition, the proxy variable Growth is included in the regression to capture the expected positive effects of options on companies' future earnings. As a result, excluding the variable Growth in the regression will help explain whether stock-based compensation expense has a negative relation with share price. On the other hand, since stock-based compensation and earnings growth are likely to be positively correlated, Growth is excluded in equation (1b) to test whether or not the forecasted earnings growth reflects the 
benefit associated with stock-based compensation. Furthermore, predicted Growth values for 2004 and 2005 are likely to be close in value since the estimation is made for five years, so the change from one year to the next is expected to be minimal. Thus, the same earnings growth forecasted values are used for 2004 and 2005.

On average, firms' share prices exceed their book value (BV). The mean (median) of stock-based compensation per share (ESO) is $\$ .100$ and $\$ .105$ (\$.070 and \$.077) in 2005 and 2004. The decrease over the year is consistent with the new adoption of SFAS No. 123R. Book value per share (BV) is $\$ 12.155$ and $\$ 11.268$ ( $\$ 10.854$ and \$10.192) in the respective years. Analysts' earnings growth forecast (Growth) is consistent across years when rounded with a mean (median) of .14 (.14), indicating that on average growth earnings are predicted to grow $14 \%$ per year over the next five years. (Annual rates of change per share are estimated from 2003-2005 to 2008-2010.) As expected, price $(\mathrm{P})$ is significantly correlated with book value, earnings per share, stock-based compensation, and earnings growth, upholding a positive association between share price and stock-based compensation value. These correlations are also interchangeably consistent with one another, further explaining that the independent variables' coefficients provide significant explanatory power across the years ( $\mathrm{F}$ stat $=16.062,10.289$ in 2005 and 2004, respectively). Adjusted $\mathrm{R}^{2}$ s from the regression are .356 and .260 in 2005 and 2004, indicating that a large portion of the variation in price is explained by stock-based compensation, ESO. The t-statistics for instrumental variables in 2005 (2004) are: for BV 3.331 (2.403), for EPS 4.113 (3.496), for ESO 2.463 (1.980), and for Growth 2.218 (2.426). All the t-statistics are significantly positive, so we reject the null hypothesis by concluding that the estimated coefficients are more than two standard errors away from zero at the $95 \%$ confidence interval level for both years. The results without the control variable Growth show more explanatory power on ESO in both years. However, omitting Growth from the regression model seems to have some effect on the adjusted $R^{2} s$. The newly tabulated $R^{2} s$ are .329 and .223 in 2005 and 2004 (versus .356 and .260), indicating that earnings growth does offer some explanation of the variation between price and employee stock options. The t-statistics also are deflated without the consideration for Growth in both years, but the change is minimal. A correlation matrix for the same variables suggests we do not have multicollinearity nor was heteroscedasticity problematic.

The results from the estimating regression provide some concrete evidence on the newly adopted cost recognition standard. Consistent with prior research, the coefficients on BV, EPS, and Growth are significantly positive in both years. As expected, the coefficient on ESO is also significantly positive in both years. If the market interprets stock option expense similar to other expense, we would expect the coefficient on ESO to be negative. Thus, the significantly positive ESO coefficient implies that companies grant stock options for the expected benefits. This tells us that stock options do not have the same characteristics as other expenses and that companies utilize stock option grants to maximize the associated benefits. Statistics from the current study reveal that the change from disclosure in one year to official recognition in the next does not have a serious effect on firms. For ESOs, the coefficients are 36.986 (30.852) in 2005 (2004). We can infer that share prices adjust positively to the formal recognition of stock-based compensation.

To determine what effects earnings growth has on stock-based compensation, the coefficient Growth was omitted from the regression model. After recalculating the regression valuation without Growth, we expect the term to have some effect on the relation between stock-based compensation expense and share price. Without the Growth term, ESO is positive and the t-statistic is even more significant, which is consistent with the belief that the benefits related to stock-based compensation are reflected in the share price. The coefficient ESO also has more significant explanatory power for share price. However, as is typical when any variable is eliminated, the adjusted $\mathrm{R}^{2} \mathrm{~s}$ decrease when the growth term is excluded from the model. Expected earnings represent not only the costs associated with stock-based compensation expense, but the incentive benefits as well.

Overall, the empirical results did not fluctuate much from 2004 to 2005, which suggests the FASB's set date for mandatory expensing did not make the market behave differently when firms began carrying stock-based compensation expense on the income statement. Specifically, results from F-tests yielded the following p-values in 2005 (2004): .001 (.018), .000 (.001), .015 (.050), and .028 (.017). The significant p-values suggest that stock prices reflect stock-based compensation expense. 


\section{CONCLUSIONS}

This study has examined the relationship between stock-based compensation expense and share price by sampling 121 (122) firms in 2005 (2004) in an attempt to capture the effect of formal cost recognition on the income statement. The results indicate that the market values stock-based compensation expense efficiently whether disclosed or recognized formally in the financial statements. Hence, the findings support the proposed hypothesis that the move from disclosure to recognition should have minimal unexpected effect on firms' bottom line earnings and share prices, because the market is efficient and the disclosed information relevant.

The move to full recognition should increase the transparency of financial reporting and help provide better information to investors in their decision making process. Ultimately, a difficulty still exists in accounting for stockbased compensation, since the SEC and FASB do not mandate the use of one valuation model. Eventually the time will come when this issue must be resolved.

\section{REFERENCES}

1. Aboody, David. 1996. Market Valuation of Employee Stock Options. Journal of Accounting and Economics. Vol. 22, Issue 1-3: 357-391.

2. Aboody, David, Mary E. Barth, and Ron Kasznik. 2001. SFAS 123 Stock-Based Compensation Expense and Equity Market Values. Working Paper (Stanford University).

3. Accounting Principles Board (APB). 1972. Accounting for Stock Issued To Employees. Opinion No. 25. New York, NY: AICPA.

4. Balsam, Steven, Eli Bartov, and Jennifer Yin. 2004. Disclosure versus Recognition of Options Expense: An Empirical Investigation of SFAS No. 148 and Stock Returns. Working Paper (Temple University).

5. Bell, Timothy T., Wayne R. Landsman, Bruce L. Miller, and Shu Yeh. 2001. The Valuation Implications of Employee Stock-Option Accounting for Computer Software Firms. Working Paper (University of North Carolina at Chapel Hill).

6. Dechow, Patricia M., Amy P. Hutton, and Richard G. Sloan. 1996. Economic Consequence of Accounting for Stock-Based Compensation. Journal of Accounting Research. Vol. 34: 1-20.

7. Delaney, Patrick R., James R. Adler, Barry J. Epstein, and Michael F. Foran. 1997. GAAP. Canada: John Wiley \& Sons, Inc.

8. Financial Accounting Standards Board (FASB). 1995. Accounting for Stock-Based Compensation. Statement of Financial Accounting Standards No. 123. Norwalk, CT.

9. ㄴ 1980. FASB Statement of Financial Concepts No. 2. Norwalk, CT.

10. 2004. Share Based Payment. Statement of Financial Accounting Standards No. 123 (Revised 2004). Norwalk, CT.

11. Harter, Charles I. and T. Harikumar. 2002. Accounting for Option-Based Compensation: The Economic Cost Approach. Journal of Business Finance \& Accounting. Vol. 29, Issue 7 \& 8: 1010-1021.

12. Li, Haidan. 2002. Employee Stock Options, Residual Income Valuation and Stock Price Reaction to SFAS 123 Footnote Disclosures. Working Paper (University of Iowa).

13. Rees, Lynn and David Stott. 1998. The Value-Relevance of Stock-Based Employee Compensation Disclosures. Working Paper (Texas A\&M University).

14. Wallman, Steven M. H. 1995. The Future of Accounting and Disclosure in an Evolving World: The Need for Dramatic Change. Accounting Horizons. Vol. 9, Number 3, 81-86. 